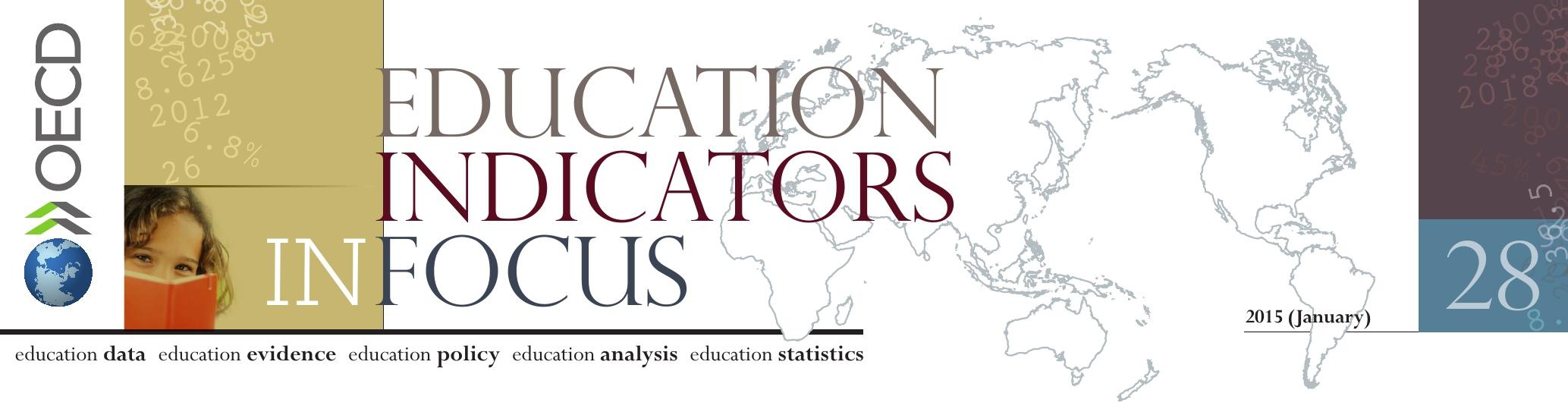

\title{
Are young people attaining higher levels of education than their parents?
}

- Between 2000 and 2012, the proportion of young adults (25-34 year-olds) with a tertiary qualification has grown by more than $3 \%$ per year on average in OECD countries.

- On average across 24 national and sub-national entities participating in the OECD Survey of Adult Skills, $39 \%$ of adults have achieved a higher level of education than their parents.

- A 20-34 year-old with tertiary educated parents is 4.5 times more likely to participate in tertiary education than a young adult whose parents did not have a tertiary qualification.

More people are benefiting from tertiary education than ever before.

Over the past decades, almost all OECD countries have seen significant increases in the educational attainment of their populations. Between 2000 and 2012 the average attainment level of the populations in OECD countries continued to increase as a result of two combined trends: the proportion of the people without upper secondary education decreased (at an average annual rate of nearly $3 \%$ ), while the proportion of people with tertiary education increased (at an average annual rate of more than 3\%). Meanwhile, the proportion of the population with an upper secondary qualification remained stable, and upper secondary attainment is still the most commonly attained level of education in most OECD countries (about $45 \%$ of adults across OECD countries). Similar trends have been seen among younger adults (25-34 year-olds).

By 2012, about one in three adults in OECD countries held a tertiary qualification, including qualifications from more technical tertiary programmes as well as from universities. This growth has been spurred by younger adults: the proportion among 25-34 year-olds was 39\%. In France, Ireland, Japan, Korea, Luxembourg, Poland and Spain, tertiary attainment rates for younger adults (25-34 year-olds) are more than 20 percentage points higher than those for older adults (55-64 year-olds).

As a consequence, between $20 \%$ and $60 \%$ of adults have a higher qualification than their parents.

As the attainment level of the population increases from generation to generation, adults may attain a higher level of education than their parents. The Survey of Adult Skills, a product of the OECD Programme for the International Assessment of Adult Competencies (PIAAC), found on average that 39\% of adults have achieved a higher level of education than their parents across 24 national and sub-national entities participating. Figures for individual countries reflect their particular pattern of expansion of attainment. For example, in Korea the dominant trend has been the increase in tertiary attainment between older and younger generations (the largest among OECD countries); in Finland, the significant increase between generations has been in the combined proportion of those with an upper secondary or tertiary qualification.

On the other hand, on average, $12 \%$ of adults have not attained their parents' education level. Nevertheless, absolute upward mobility in education is more common than absolute downward mobility in all the participating countries, reflecting the expansion of education systems (Figure 1). 
Figure 1. Percentage of 25-64 year-old non-students whose educational attainment is higher (upward mobility) or lower (downward mobility) than that of their parents (2012)

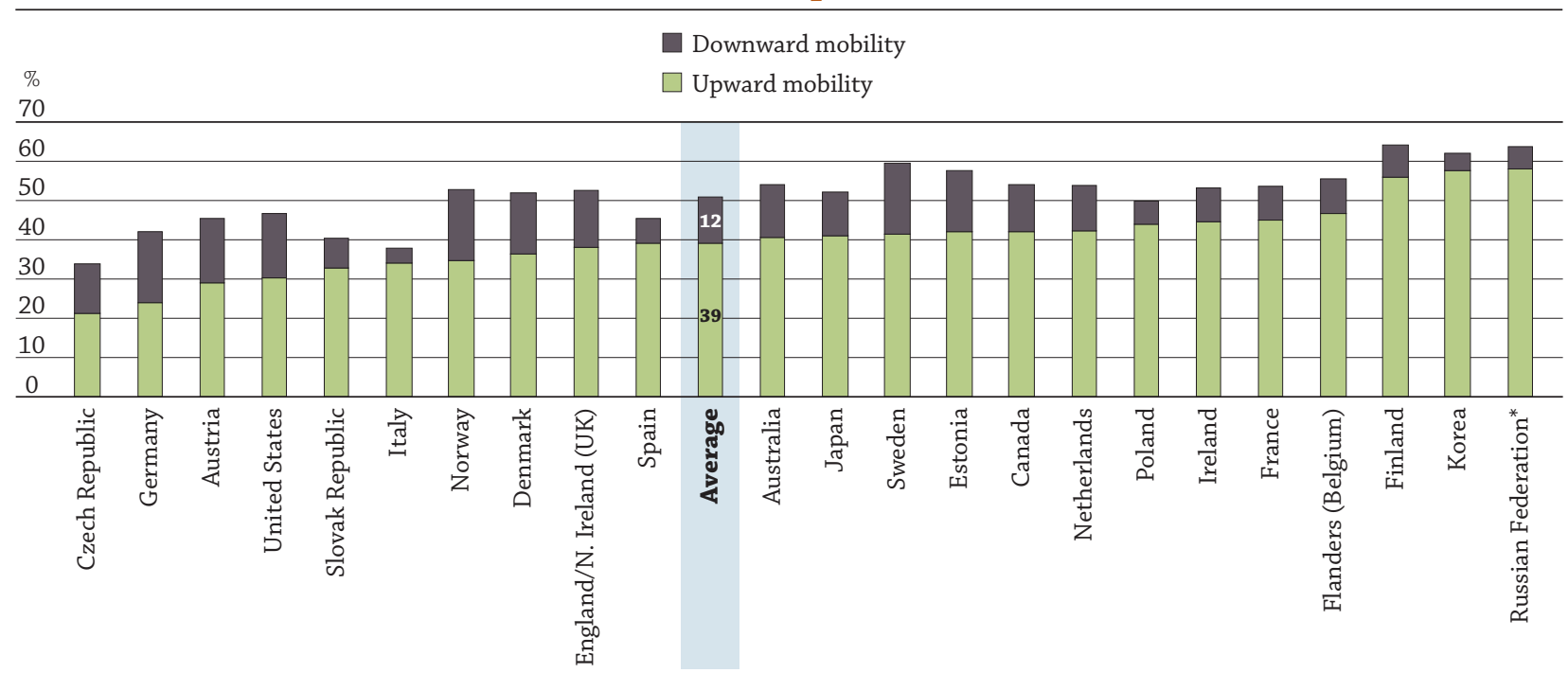

* See note on data for the Russian Federation at the bottom of page 4.

Countries are ranked in ascending order of the proportion of adults with upward mobility with respect to the educational attainment of their parents. Source: OECD (2014), Education at a Glance 2014: OECD Indicators, Indicator A4 (www.oecd.org/edu/eag.htm).

But close to half of all adults have the same education as their parents.

In most countries, at least $40 \%$ of non-student adults have the same educational attainment as their parents (status quo), and in Austria, the Czech Republic, Germany, Italy, Poland, the Slovak Republic, Spain and the United States, this figure is over $50 \%$ (Figure 2).

Figure 2. Percentage of 25-64 year-old non-students with similar educational attainment to their parents (2012)

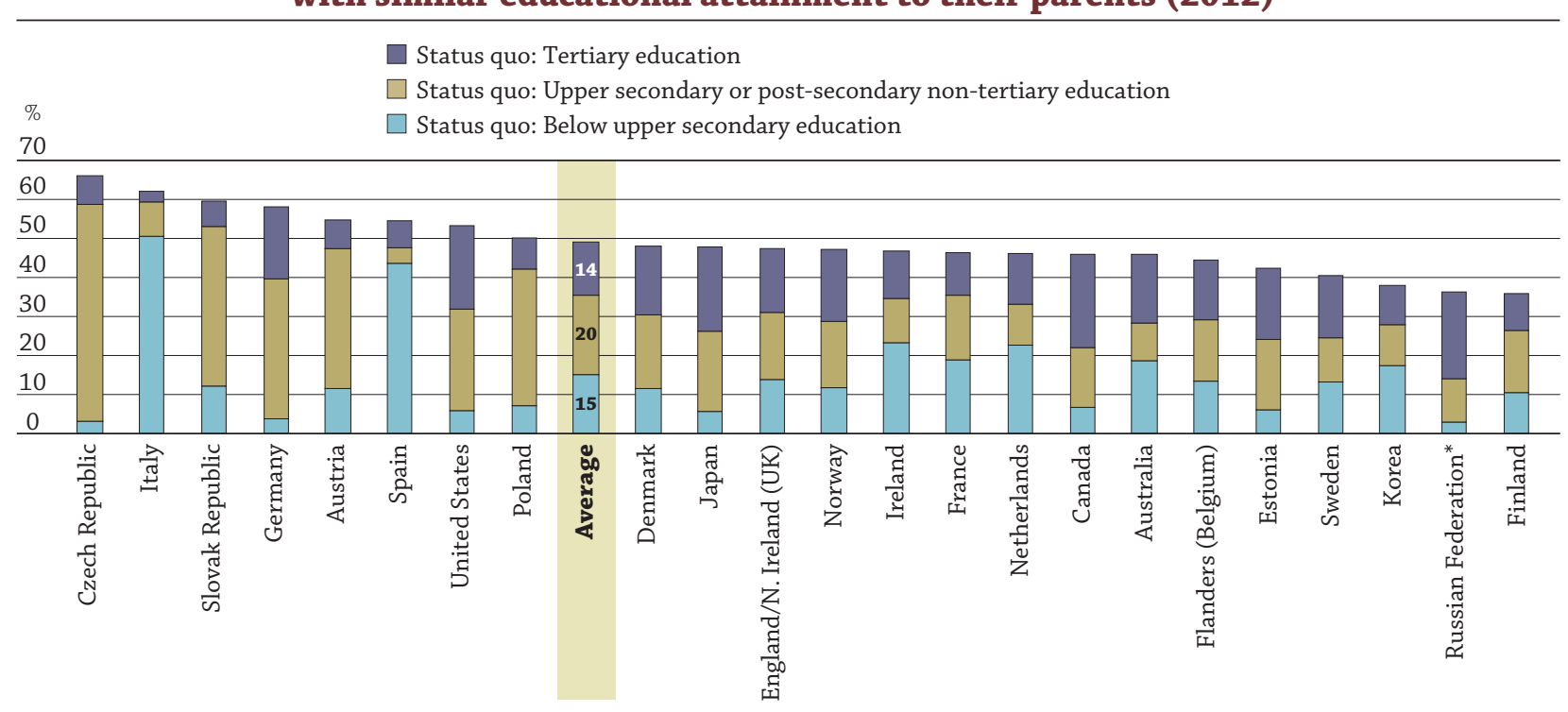

* See note on data for the Russian Federation at the bottom of page 4.

Countries are ranked in descending order of the proportion of adults with the same educational attainment as their parents.

Source: OECD (2014), Education at a Glance 2014: OECD Indicators, Indicator A4 (www.oecd.org/edu/eag.htm). 
Educational status quo between generations is particularly worrying when it means the younger generation reproducing the low level of education of their parents. For instance, in Italy and Spain between $40 \%$ and $50 \%$ of 25-64 year-olds have not attained upper secondary education, as either of their parents. In Austria, the Czech Republic, Germany, Poland and the Slovak Republic, 35\% or more of the adult population have the same upper secondary or post-secondary non-tertiary education as at least one of their parents.

Similar overall proportions of educational status quo among adults can mask different country profiles. For example, in both Austria and Spain, 55\% of 25-64 year-olds have a similar level of attainment as their parents, but in Spain most of these adults did not reach the end of secondary education, whereas in Austria most have an upper secondary level of education. The educational attainment in these countries is different: in Spain $45 \%$ of adults do not have an upper secondary education while in Austria $63 \%$ of adults have an upper secondary or a post-secondary non-tertiary education. Therefore, these countries face different challenges in increasing the education level of their populations.

\section{Educational upward mobility is slowing among younger generations.}

On average across countries participating in the Survey of Adult Skills, the percentage of adults with a higher level of education than their parents is stable among older adults: $42 \%$ of $55-64$ year-olds and $43 \%$ of $45-54$ year-olds. However, the proportion falls for the younger generations: $38 \%$ of $35-44$ year-olds and $32 \%$ of $25-34$ year-olds. Most countries follow a similar pattern with upward mobility slowing for the younger generations. The exceptions are Italy and Spain, where upward mobility is higher among the younger generations.

The likelihood to enrol in tertiary education varies according to parent educational background. According to the Survey of Adult Skills, on average $55 \%$ of $20-34$ year-old students in tertiary education have at least one parent who has completed that level of education. This could reflect the fact that the population with tertiary education is already large, or it could result from some equity issues such as the education system failing to help young people whose parents do not have a tertiary qualification to attend tertiary education.

\section{Figure 3. Relationship between the share of upward mobility among 25-34 year-olds and the likelihood of participating in tertiary education for 20-34 year-olds (values in reverse order) (2012)}

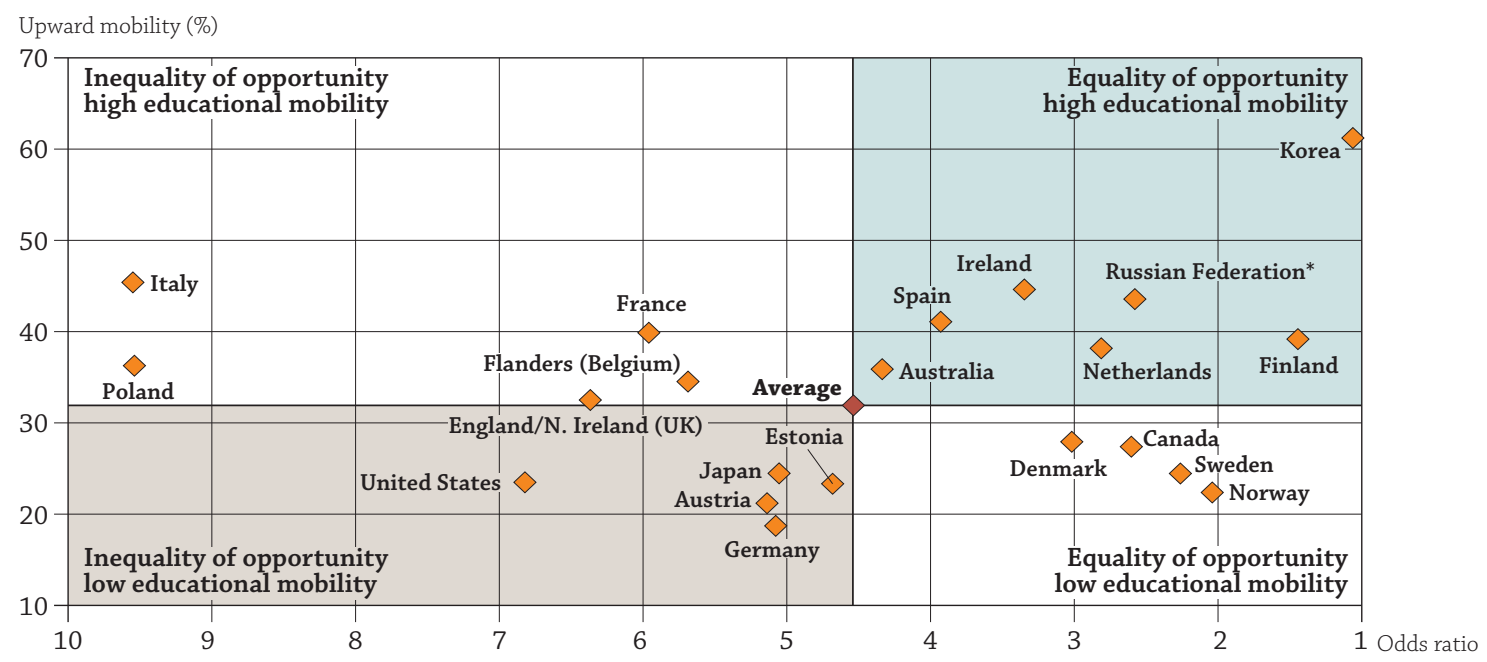

* See note on data for the Russian Federation at the bottom of page 4 .

Note: Mobility refers to the educational attainment of 25-34 year-old non-students compared with their parents' educational attainment, and equality of opportunity, measured through the likelihood of participating in tertiary education, refers to the 20-34 year-old students attending tertiary education (odds ratio) with at least one parent with tertiary education.

Source: OECD (2014), Education at a Glance 2014: OECD Indicators, Indicator A4 (www.oecd.org/edu/eag.htm). 


\section{EDUCATION INDICATORS IN FOCUS}

education data education evidence education policy education analysis education statistics

$\stackrel{2}{\infty}$

ம

50

$18 \cdot 4_{3}^{2} 8_{36}^{2} \cdot 3_{5}^{2} 2^{2} 0_{5}$

As Figure 3 shows, even among countries with similar levels of upward educational mobility, students'

$6 \%$ likelihood of attending tertiary education may be very different. For instance, in both Italy and Ireland around $45 \%$ of non-student 25-34 year-olds have attained an educational level higher than their parents. However in Italy a 20-34 year-old whose parents have a tertiary education is about 10 times more likely to participate in tertiary education than someone whose parents have below upper secondary education; in Ireland the figure is about 3 times (the average across participating countries is 4.5).

These differences can be down to various factors, such as financial barriers to entering tertiary programmes due to high tuition fees or lower financial support for continuing studies; or the financial incentives to graduate from tertiary education, considering the relative financial returns of education versus labour market opportunities.

Odds ratio reflects the relative likelihood of participating in tertiary education for individuals whose parents have a tertiary qualification relative to individuals whose parents have a below-tertiary qualification. An odds ratio of 1 represents equal chances of participating in tertiary education whatever the educational background of their parents (equity). Coefficients with a value below 1 indicate that there is less chance of participating in tertiary education for individual whose parents have a tertiary qualification compared to individuals whose parents have a below-tertiary qualification (inequity), and coefficients greater than 1 represent greater chances (inequity).

Data on educational attainment for most countries are taken from OECD and Eurostat databases which are compiled from National Labour Force Surveys by the OECD LSO (Labour Market, Economic and Social Outcome of Learning) Network. Data on educational mobility are based on 24 national and sub-national entities participating in the 2012 Survey of Adult Skills (PIAAC). For more detail on countries included in these analyses, see Annex 3 of Education at a Glance 2014: OECD Indicators (www.oecd.org/edu/eag.htm).

The bottom line: Over the past decades, the proportion of tertiary educated adults increased in all OECD countries. By 2012, among countries with available data, a significant proportion of adults have a higher level of attainment than their parents. Upward educational mobility may be falling among younger generations as the population has a higher educational level. Still, young people with tertiary educated parents are more likely to participate in tertiary education than those whose parents did not have a tertiary qualification.

\section{For more information}

OECD (2014), Education at a Glance 2014: OECD Indicators, OECD Publishing, Paris, http://dx.doi.org/10.1787/eag-2014-en.

\section{Contact}

Étienne Albiser (Etienne.Albiser@oecd.org) / Gara Rojas González (Gara.RojasGonzalez@oecd.org).

\begin{tabular}{l|l}
\hline Visit & Coming next month \\
$\begin{array}{l}\text { www.oecd.org/edu/eag.htm } \\
\text { Education Indicators in Focus (previous issues) }\end{array}$ & \\
\hline PISA in Focus & \\
\hline Teaching in Focus & \\
\hline
\end{tabular}

Photo credit: ( ) Ghislain \& Marie David de Lossy/Cultura/Getty Images

This paper is published under the responsibility of the Secretary-General of the OECD. The opinions expressed and arguments employed herein do not necessarily reflect the official views of OECD member countries.

This document and any map included herein are without prejudice to the status of or sovereignty over any territory, to the delimitation of international frontiers and boundaries and to the name of any territory, city or area.

Note for the Russian Federation in the Survey of Adult Skills (PIAAC)

Readers should note that the sample for the Russian Federation does not include the population of the Moscow municipal area. The data published, therefore, do not represent the entire resident population aged 16-65 in Russia but rather the population of Russia excluding the population residing in the Moscow municipal area. More detailed information regarding the data from the Russian Federation as well as that of other countries can be found in the Technical Report of the Survey of Adult Skills (OECD, forthcoming). 